IZA DP No. 6591

Are Relative-Income Effects Constant across the Well-being Distribution?

Santiago Budría

May 2012 


\title{
Are Relative-Income Effects Constant across the Well-being Distribution?
}

\author{
Santiago Budría \\ CEEApIA and IZA
}

\author{
Discussion Paper No. 6591 \\ May 2012
}

\author{
IZA \\ P.O. Box 7240 \\ 53072 Bonn \\ Germany \\ Phone: +49-228-3894-0 \\ Fax: +49-228-3894-180 \\ E-mail: iza@iza.org
}

\begin{abstract}
Any opinions expressed here are those of the author(s) and not those of IZA. Research published in this series may include views on policy, but the institute itself takes no institutional policy positions.

The Institute for the Study of Labor (IZA) in Bonn is a local and virtual international research center and a place of communication between science, politics and business. IZA is an independent nonprofit organization supported by Deutsche Post Foundation. The center is associated with the University of Bonn and offers a stimulating research environment through its international network, workshops and conferences, data service, project support, research visits and doctoral program. IZA engages in (i) original and internationally competitive research in all fields of labor economics, (ii) development of policy concepts, and (iii) dissemination of research results and concepts to the interested public.
\end{abstract}

IZA Discussion Papers often represent preliminary work and are circulated to encourage discussion. Citation of such a paper should account for its provisional character. A revised version may be available directly from the author. 


\section{ABSTRACT
Are Relative-Income Effects Constant across the Well-being Distribution?*

This paper challenges the common assumption made by economists to date that income comparisons are similarly important in different segments of the subjective well-being (SWB) distribution. The results, based on the 2000-2007 waves of the German SOEP and on a Generalized Ordered Probit for panel data, show that relative income, as measured either by the mean income of the reference group or the individual ordinal ranking within the group, exerts a differential effect across SWB levels. Such divergence is assessed by means of the tradeoff ratio between household income and the relative income variables. The results show that a low rank and falling below the average income in one's group are significant determinants of low SWB but largely irrelevant when accounting for high SWB. The fact that conditionally unhappy individuals are more sensitive to comparisons, particularly if they are unfavorable, is consistent with earlier laboratory studies in the field of psychology.

JEL Classification: D62, I31

Keywords: subjective well-being, comparison income, income rank, generalized ordered response model

Corresponding author:

Santiago Budría

Department of Economics

University of Madeira

Rua Penteada 9000-390

Funchal

Portugal

E-mail: sbudria@uma.pt

\footnotetext{
* The financial support from the Spanish Ministry of Education through grant ECO2008-04321 and the Junta de Andalucía through grant P07-SEJ-03261 is gratefully acknowledged. Part of this research was developed during a research visit at the Department of Economics of the University of Verona. The author thanks the faculty members for their warm hospitality.
} 


\section{Introduction}

Easterlin's $(1974,1995)$ famous paradox states that while richer individuals in a country are happier than their poorer fellows, income increases over time do not lead to improvements in overall well-being. This observation has produced a lively empirical and theoretical literature revolving around potential solutions for the puzzle. One of the most accepted explanations is at the core of Easterlin's original insights: increases in personal income lead to higher individual well-being, but this effect is strongly moderated by comparison processes in which failing to keep up with the societal peers (frequently termed "the Joneses”) makes a person less happy.

The comparison income hypothesis is the dominant framework of income externalities and suggests that individuals care about how their income compares with the norm of a reference group. This hypothesis has found sound empirical support in studies showing that the income norm negatively and significantly predicts different domains of well-being (see Senik, 2005 and Clark et al., 2008a for a review). The results are typically based on econometric regression of individual self-reported well-being over a set of personal and demographic characteristics in which household income and the comparison income level are included as additional regressors. The underlying model has the form

$$
S W B=f\left(S W B^{*}\left(X, y, y^{c}\right)\right)
$$

where $S W B$ is some self-reported level of well-being, $S W B^{*}($.$) is to be thought of as the$ person's true well-being or utility, $f($.$) is a continuous function relating actual to reported$ well-being, $X$ is a set of demographic and personal characteristics, $y$ is personal income and $y^{c}$ stands for comparison income.

A limitation of the literature to date is that the comparison income effect has been calculated in an "average" sense, i.e., assuming that keeping up with the Joneses is as important in the lower as in the upper segments of the SWB distribution. Technically, this assumption stems from the fact that in models based on the cardinalization of the dependent variable as well as in standard ordered response models the gradient vector is the same for 
all outcomes of the dependent variable. Under cardinality, the empirical counterpart of Eq. (1) is

$$
S W B=X \beta+\alpha y+\alpha_{c} y^{c}
$$

where the impact of comparison income on reported well-being, $\alpha_{c}$, is restricted to be constant across the SWB distribution. This is also the case of the Ordered Probit (OP) and, more generally, ordered response models, where the latent function has several threshold points that determine the observed value of SWB,

$$
f\left(\operatorname{SWB}^{*}\left(X, y, y^{c}\right)\right)=j \text { if } \delta_{j-1} \leq X \beta+\alpha y+\alpha_{c} y^{c}<\delta_{j}
$$

for $j=1, \ldots, J$, with $J$ being the number of possible outcomes and $-\infty=\delta_{0}<\delta_{1} \ldots<\delta_{J}=\infty$. A related simplification is a tradeoff ratio between comparison and own income, $\alpha_{c} / \alpha$, that is constant across SWB levels. This ratio is a key equivalence scale insofar as it measures the percentage change in personal income that would provide the same SWB effect as a onepercentage decrease in comparison income. The accurate appraisal of this compensation is crucial to ascertain whether SWB is totally relative in income, as suggested in previous research.

This paper asks: are relative income effects constant across SWB levels? To answer this question, the paper uses data from the 2000-2007 waves of the German Socio-Economic Panel dataset (SOEP) and a Generalized Ordered Probit (GOP) extended to panel data. Pioneered by Boes and Winkelmann (2009), the main advantage of the GOP is that it allows for a differential effect of the covariates in the different outcomes of the dependent variable. In the setting outlined above, such refinement corresponds to allowing the parameters $\alpha$ and $\alpha_{c}$ to differ across SWB levels. This empirical strategy aims at providing novel insights on how and to what extent the interplay between other's income and SWB changes across the distribution.

The paper makes three contributions to the literature. First, it assesses the extent and statistical significance of differences in the well-being costs of comparison income between individuals with identical observable characteristics but with differing levels of SWB. By 
examining such variations, the paper challenges the common assumption made in the economics literature to date that conditionally happy and unhappy individuals respond similarly to social comparisons. This research question is inspired in consistent evidence from the field of psychology pointing to relevant differences between happy and unhappy people regarding their response to hedonically relevant information, including social comparisons. These two groups are found to differ in how they blame or credit themselves for specific achievements, how they manipulate social comparison information, how they use such information and how they respond to it. Comparison information appears to hurt unhappy individuals when it is unfavorable, but does not help them when it is favorable. By contrast, happy individuals do not appear to be hurt by unfavorable social information (Lyubomirsky and Ross, 1997 and Lyubomirsky et al., 2001). These results are however mostly based on comparisons in terms of cognitive and academic performance, chronic diseases and relations quality. This paper explores whether they are extensible to the realm of economic comparisons.

As a second contribution, the paper considers two models of income comparisons simultaneously. The comparison income hypothesis has been challenged by other interpretations of the data according to which people gain utility from occupying a higher ranked position within the reference group rather than from outpacing the mean level of the group. In the setting outlined above, focusing on rank effects rather than on income benchmarks corresponds to replacing the reference income level $y^{c}$ by the individual relative position in the group, $r$. There are a number of intuitive arguments as to why a rankbased status matters to human beings. According to range-frequency theory (Parducci, 1995), subjects make category ratings relative to their position between the endpoints of the stimulus range and according to their percentile rank. The rank-based status might have neurobiological underpinnings, serve an evolutionarily useful informational role and dramatically influence the physical and psychological health of an individual (Zizzo, 2002; Sapolsky, 2004). Recent work has shed light on the direction and magnitude of the rank effect on job and economic satisfaction (Brown et al., 2008; Clark et al., 2009a), individual perception on own economic position (Powdthavee, 2009), work effort (Clark et al., 2010) and SWB (Boyce et al., 2010). Whether these effects are similar for individuals with diverging levels of SWB is a question that remains to be answered. 
The third contribution has to do with the estimating strategy. A common concern with selfreported data is the existence of omitted individual characteristics that simultaneously influence the dependent and the explanatory variables. This set of idiosyncratic variables, rooted to personality in the present context, is likely to operate through three channels. Firstly, by biasing SWB scores due to the correlation of specific personality traits (extraversion, neuroticism, self-esteem) with self-reported measures of affect and satisfaction (Diener and Lucas, 1999; Judge et al., 2002). Secondly, by mediating the impact of comparison information on SWB. This concern is motivated by a corpus of field and laboratory studies in psychology documenting a close relationship between personality and the responsiveness to social comparisons ${ }^{1}$. The third channel of correlation is with the right-hand side variables, especially income. If outgoing and extroverted people are more successful in life, then a higher income is a prize rather than a causal factor of happiness (Graham et al., 2004).

In sum, the problem of unobserved heterogeneity calls for the use of individual effects; ideally, for a fixed effect (FE) model in which the idiosyncratic components are fully factored out from the results. However, FE models have no standard way to date of allowing the estimated parameters to differ between outcomes of the dependent variable. The GOP allows for this possibility but, in turn, is a random-effects (RE) model. As such, it cannot preclude the possibility that the personality-driven random term of each individual is correlated with the observables. To deal with these caveats, the estimating model introduces i) a Mundlak term that corrects the potential correlation between the errors and the explanatory characteristics; and ii) explicit controls for the respondents' personality traits. In this respect, it takes advantage of the 2005 GSOEP wave, which includes personality indicators based on the well-known Big Five Inventory (BFI) and a set of complementary questions aimed at measuring the respondents' locus of control

\footnotetext{
${ }^{1}$ The available evidence indicates that: i) those who are low on self-esteem or depressed are less likely to improve their mood after comparing with worse-off others and respond more negatively after comparing with better-off others (Wheeler and Miyake, 1992; Aspinwall and Taylor, 1993); ii) neurotic people respond more negatively to social comparisons, regardless of whether they are downwards or upwards (Van der Zee et al., 1998); and iii) comparisons pose a threat to the self when individuals feel they cannot determine their standing on the comparison dimension, or, to put it another way, the relative importance of downwards and upwards comparisons depends on the individual's locus of control (Wood and VanderZee, 1997).
} 
(LOC). Such an extension is interesting on its own as it provides fresh insights on the extent of income comparisons when personality differences are explicitly controlled for.

The rest of the paper is organized as follows. Section 2 reviews previous estimates of relative-income effects. Section 3 outlines the different specifications used in the paper and the research hypotheses. Section 4 describes the dataset and the estimation procedure. Section 5 presents the results and discusses their robustness to changes in the definition of the reference group. Section 6 presents the concluding remarks and lines of further research.

\section{Background and previous findings}

The concepts of deprivation, relative standards, social aspirations, habituation and downward-upward comparisons have long been used within the field of sociology and psychology to understand how individuals operate within and are influenced by reference groups. Although recognition of these influences is somewhat more recent in economics, the evidence accumulated to date is substantial. In just a few years the distinction between absolute and relative formulations of utility has proven to be a useful concept for rationalizing a large set of unexplained phenomena in a variety of fields, including asset pricing (Campbell and Cochrane, 1999; Abel, 2008), growth (Carroll at al., 2000), consumption behavior (Fuhrer, 2000) and wealth inequality (Díaz et al., 2003). Advances at the theoretical level have run parallel to a new wave of empirical papers assessing the importance of relative effects for determining SWB by means of large scale datasets and self-reported data. A recent survey by Van Praag and Ferrer-i-Carbonell (2010) provides thorough discussions on the implications of these externalities for a variety of policyrelevant issues at the micro and the macro level, including optimal taxation, public redistribution and the welfare costs of aggregate fluctuations.

\subsection{A practical question: the definition of reference groups}

Researchers in the field usually have to decide by themselves how to identify a relevant group, and then show that the reference income or the individual rank within that group 
significantly accounts for some variation of the dependent variable. Some authors rely on a pure geographical approach by assuming that comparisons take place among people living in the same geographical area. The level of aggregation varies greatly across studies, though, ranging from countries (Di Tella et al., 2003) and American states (Blanchflower and Oswald, 2004) to German neighborhoods containing 25 households on average (Dittmann and Goebel, 2010). Intermediate levels of aggregation (between 100,000 and 2,500 people) include Public Use Microdata Areas in the US (Luttmer, 2005), census tract in Canada (Helliwell and Huang, 2010) and Indonesian sub-districts (Powdthavee, 2009). Other authors refer to comparisons within cohorts (McBride, 2001) and in the workplace (Brown at al., 2008). Senik (2004) estimates a person's reference income as the predicted income of people with similar characteristics (education, experience, region, age, gender and, among the employed, branch and occupation code). Ferrer-i-Carbonell (2005) and later on Boyce et al. (2010) use a cell-mean approach based on a combination of four socio-economic criteria (age, education, gender and region).

A related body of research has directed efforts toward understanding the endogenous determination of reference groups by directly asking individuals about the direction of their comparisons (Falk and Knell, 2004; Senik, 2009; Clark and Senik, 2010). The evidence points to some degree of heterogeneity in the choice of the relevant groups. In an endogenous context, however, assessing the impact of income comparisons upon SWB would require gathering data on the groups pointed out by the individual, thus rendering the analysis unfeasible outside a laboratory. A related concern is that, due to data limitations, it remains to be tested whether the self-reported importance of the different groups is a good predictor of their actual importance in a SWB equation.

\subsection{Empirical estimates of the comparison income effect}

Relative income effects are prevalent in the literature. However, a review of the estimates gives rise to some comparability problems. Differences across studies in terms of SWB scales, alternative cardinal and ordinal models, and differences in the measurement of income obscure the comparison of results. Given this caveat, a more relevant question is: how large is the comparison income effect relative to own income? As this equivalence 
scale is not explicitly calculated in most papers, the following review attempts to provide an integrative view on the subject by picking up from different studies the tradeoff ratio implied by the point estimates.

Ferrer-i-Carbonell (2005) uses data from the 1992-1997 waves of the GSOEP to estimate a set of SWB equations. The results are based on an OP with a Mundlak correction term. She differentiates between transitory and permanent family income by noting that family $i$ income at time $t, y_{i t}$, can be written as a function of the average income over the $\mathrm{T}$ waves and a deviation from this level, $y_{i t}=\bar{y}_{i}+\Delta y_{i t}$. In the most parsimonious specification (Table 2 , pp. 1011), the implied tradeoff between comparison and family income, $\alpha_{\mathrm{c}} / \alpha$, amounts to -0.91 and -0.32 depending on whether changes in family income are transitory or permanent. These figures, below unity, change slightly across specifications and suggest that SWB is not entirely relative in income.

These estimates are remarkably stable across studies. Blanchflower and Oswald (2004) use ordered logits and pooled Canadian and UK data to estimate SWB equations for different periods. Their results imply a tradeoff ratio between comparison and family income of some -0.65 for the 1972-98 period in the US and -0.48 between 1975 and 1998 in the UK. In Helliwell and Huang (2010) the corresponding figure ranges from -0.64 to -0.86 across estimating samples. Their results are based on an OP model and a set of Canadian crosssection datasets. The calculations in McBride (2001) are also cross-sectional. In his dataset, the 1994 wave of the US GSS, the income variable is coded in intervals. While such coding is unlikely to distort the calculation of the aggregate income level within the reference groups, it arguably restricts the ability of the model to relate individual differences in personal income to differences in SWB. The correlation is indeed very small, and the resulting tradeoff ratio is remarkably high (-5.3). Luttmer (2005) uses panel data from the US to estimate a set of pooled OLS and fixed-effects linear regressions. Using a pure geographic approach for the definition of reference groups, his baseline specification yields a coefficient of comparison income $(-0.239)$ that is 1.9 times the coefficient of household income (0.123). Still, in a more refined model he finds that an increase in the benchmark income and a similarly sized increase in own income does not affect SWB. Senik (2009) uses cross-section data from 28 countries included in the Life in Transition Survey to focus 
on the different comparison groups declared by respondents in her sample. The results, based on a set of self-assessed questions on the individual economic performance relative to other groups, uncover significant negative effects of other's economic position on individual SWB.

In an earlier work, Senik (2004) finds a positive, not negative, effect of comparison income on SWB. Her results, based on the Russian population during the 1994-2000 transition period, suggest that under increasing uncertainty the status effect (whereby comparison income makes people feel relatively deprived) can be more than offset by a signal effect according to which a higher income of the reference group makes people optimistic about their own future prospects. A similar result has been reported by Clark et al. (2009b) using job satisfaction data and comparisons within the workplace.

\subsection{Rank effects}

People may gain utility from occupying a higher ranked position within the reference group rather than from making more income than the Joneses. Clark et al. (2009a) match individual economic satisfaction scores from eight years of ECHP data to measures of own income and neighborhood income distribution. Their fixed-effects linear estimator finds evidence that economic satisfaction depends significantly and positively on the household's normalized rank in the neighborhood. Specifically, a 1-decile increase in rank is as important ceteris paribus as a 1.6 unit increase in log income or, to put it another way, as a rise in absolute income by a factor of almost 5. Based on Indonesian cross-section data, Powdthavee (2009) provides very similar estimates. Focusing on individual perception on own relative economic position, he finds that individual ranking within the reference group (given by the individual administrative village) is a more relevant dimension than the mean income level of the group. Powdthavee differentiates between income and expenditures, finding that the latter tend to exert a larger and more significant effect on the dependent variable. The results from the more refined model suggest that a 1-decile improvement in the rank of expenditures is as important for the perception of own relative position as a 4.24 factor increase in household expenditures. 
These estimates are remarkably large; probably due to the close relationship between individual rank and the perception of and satisfaction with own economic position. Studies based on broader assessments report substantially lower figures. Brown et al. (2008) use 1998 cross-section data from the UK to examine satisfaction with different job domains. Despite that different specifications are used in the analysis, the results in the preferred model suggest that a 1-decile increase in rank can raise satisfaction with pay as much as a 12.7\% increase in earnings. In a work by Boyce et al. (2010) using SWB data, the authors test the comparison income against the income rank model and find evidence in favor of the latter. In their estimates, household income is not a significant variable, while a 1-decile increase in rank has an impact of 0.03 points on a 1-7 SWB scale.

\section{Method of analysis}

\subsection{Specification and research hypotheses}

SWB is assumed to be a sufficiently general function to accommodate the two dominant ways in which social comparisons have been modeled in the economics literature: the comparison income and the rank model

$$
S W B=f\left(S W B^{*}\left(X, y, y^{c}, r\right)\right)
$$

As household income tends to be stronger than individual income in explaining SWB (Helliwell and Huang, 2010), in the present paper individual income $y$ is operationalized as family income. Rank is defined as the position of individual $i$ in terms of her family income as a proportion of the number of individuals in group $g$. This is calculated as $\left(\mathrm{P}_{\mathrm{ig}}{ }^{-}\right.$ $1) /\left(N_{g}-1\right)$, where $P_{\text {ig }}$ is the position, in ascending order, of individual $i$ in group $g$, and $N_{g}$ is the number of individuals in the group. Normalized rank is exactly zero for the poorest individual, and one for the richest individual.

The empirical analysis will be based on four different specifications of Eq. (4). The first two specifications assume that SWB depends on comparison income but not on rank. 
Apart from vector $X$ and income $y$, specification 1 includes the average income of the reference group, and is used to test the first research hypothesis:

Question 1: Is the tradeoff ratio between family and comparison income constant across the SWB distribution?

Studies to date have typically assumed that the socio-economic factors that put a person in the upper and the lower range of the SWB distribution are the same. However, the determinants of happiness may differ significantly from the determinants of unhappiness. Such a distinction is consistent with psychological studies showing that subjective measures of satisfaction are a construct of various pleasant/positive and unpleasant/negative emotions, with the specific mechanisms that give rise to each being largely independent (Huppert and Whittington, 2003). Hence, it may well be that comparison income is a more relevant source of unhappiness (when high) than of happiness (when low) and that, relative to individual income, its importance varies across SWB levels. Question 1 explicitly addresses this issue.

Specification 2 moves on to allow for a differential effect of comparison income depending on whether the individual is below or above the reference group. It has been documented that while individuals' well-being is negatively influenced if they fall below the reference group, having an income above their benchmark does not make an individual much happier (Ferrer-i-Carbonell, 2005; Senik, 2009). To allow for these effects, specification 2 decouples comparison income into two different variables termed richer and poorer:

If $y \geq y^{c}$ : richer $=y-y^{c}$ and poorer $=0$

If $y<y^{c}:$ richer $=0$ and poorer $=y^{c}-y$

Based on previous results, the coefficient of poorer is expected to be larger in magnitude than the coefficient of richer. Specification 2 is used to test a second research hypothesis:

Question 2: Is the importance of being richer and poorer than the reference group similar across segments of the SWB distribution? 
Specification 3 switches to a pure rank model. In this case, SWB is assumed to depend only on the individual rank within the group and not on the group's average income. This specification is used to answer the following question:

Question 3: Does the tradeoff ratio between individual income and rank differ across the SWB distribution?

Finally, specification 4 assumes that SWB depends on both comparison income and rank. This extension is aimed at providing an assessment of which of the two effects is more prevalent for determining SWB. Based on the studies surveyed in the previous section, the rank effect is anticipated to be larger than the comparison and the personal income effect. The last research hypothesis is whether this prevalence holds in all segments of the SWB distribution:

Question 4: Is income rank the most relevant source of low and high SWB?

\subsection{Definition of reference group}

The identification of reference groups is based on a mixed approach in which several demographic dimensions are considered simultaneously. As in Ferrer-i-Carbonell (2005), the sample individuals are partitioned according to i) geographical region (West or East Germany), ii) gender, iii) educational attainment (less than 10, 10, 11, 12 and more than 12 years of schooling), and iv) age (younger than 25, 25-34, 35-44, 45-64 and older than 65). The combination of these criteria produces 100 different groups. An individual in a specific group is assumed to have a comparison income level which she knows is the average income of an individual like her. Similarly, rank is given by the relative position within that specific cell.

Note that the reference group is defined at the individual rather than at the household level. Individuals are regarded to have their own reference group, which is not always the same as the one of their partner, while they are assumed to pool income within the household (this is, the income they enjoy is equal to the family income). 


\section{Data and estimation procedure}

\subsection{Data}

Conducted in Germany since 1984, the SOEP is a wide-ranging, representative longitudinal study of households that contains a large set of personal, family and labor market characteristics of household members. In 2005 the panel includes a set of questions aimed at capturing various concepts of personality: the BFI and LOC. Since these questions were only asked in 2005 and despite the fact that personality traits tend to be quite time consistent (see section 4.2.1), the empirical analysis will focus on the years around 2005 only. In concrete we use years 2000 to 2007.

To ensure the maximum representativity of the reference groups, the data is filtered using a two-stage procedure. The first stage consists in retaining individuals with non-missing information for income and the four demographic dimensions used to define the groups. This renders a total of 161,596 person-year observations, from which the yearly average income of the 100 reference groups and the corresponding ranks are computed. The average number of individuals in a group ranges from a minimum of 10 to a maximum of 4,484 with an average of 1649.4 (SD = 1713.3). The second stage proceeds with the filtering by dropping observations with missing values in the model covariates, including individuals who did not complete the 2005 module of personality. This results in a final sample of 126,752 observations.

In the SOEP, the well-being question is

- How happy are you at present with your life as a whole?

The candidate answers take discrete values from 0 to 10 and will be referred to as SWB hereafter. Despite a long tradition among sociologists and psychologists, subjective data was subject to criticism by economists concerned about the potential biases arising from cultural differences, framing problems, cognitive bias and mood effects. For reasons of 
space, the present paper overlooks such a discussion by simply noting that the evidence accumulated over recent years in top international journals has persuaded most readers about the validity and consistency of this measurement method. In a nutshell, subjective measures of satisfaction and well-being have a predictive power over relevant actions and are related (in the expected direction) to a number of objective indicators, including physical health and longevity (Danner et al., 2001), suicide rates and macroeconomic fluctuations (Di Tella et al., 2003), unemployment (Clark et al., 2008b) and quality of life (Clark and $\mathrm{Wu}, 2010)$. They also show a reasonable amount of internal consistency and temporal reliability: they correlate well with one another and with alternative methods of measurement, including ratings made by family and friends, facial measures of emotion and a vast array of psychological and psychosocial indicators (Cacioppo et al., 2008).

Table 1 contains the summary statistics of the estimating sample. The average SWB over the sample period is about 7.0 ( $\mathrm{SD}=1.66)$. Average family income amounts to 2,922 euros, while the average educational attainment is 12.08 years of schooling. Men account for $47.9 \%$ of the sample. Most individuals are married or live with a partner (64.7\%), are employed (63.0\%) and live in West Germany (74.6\%). In the regression stage, the family and comparison income variables are entered in their logarithm form ${ }^{2}$. Incomes are additionally transformed into real terms using the yearly consumer price index.

Insert Table 1 about here

\subsection{Estimating procedure}

Reported SWB is assumed to be a function of a latent variable SWB* that is not measured, is continuous, has several threshold points that determine the observed value of SWB, and is a function of observable characteristics

$$
S W B_{i t}^{*}=\beta X_{i t}+\alpha_{l} \bar{y}_{i}+\alpha_{s} y_{i t}+\alpha_{c} y_{i t}^{c}+\alpha_{r} r_{i t}+v_{i}+\eta_{i t}
$$

\footnotetext{
${ }^{2}$ Given the approximately normal distribution of log income, the comparison income in the estimating equation can be regarded as the 'typical' income level of the group.
} 
where $v_{i}$ is an individual (random) effect and $\eta_{i t}$ a pure error term. $X$ is a vector with $K-1$ explanatory variables, including age and age squared, years of completed education, household size (number of children and number of adults at home) and additional dummy variables for gender, marital condition, employment status, health condition, region and year fixed effects. The specification used in the paper closely follows the myriad of models surveyed in van Praag and Ferrer-i-Carbonell (2008) in that it includes variable $\bar{y}_{i}$. This covariate stands for the average of $y_{i t}$ over the $T$ years in the panel. Since $\alpha_{l} \bar{y}_{i}+\alpha_{s} y_{i t}=\left(\alpha_{l}+\alpha_{s}\right) \bar{y}_{i}+\alpha_{s} \Delta y_{i t}$, this refinement allows us to assess how changes in family income affect SWB depending on whether they are permanent $\left(\alpha_{l}+\alpha_{s}\right)$ or transitory $\left(\alpha_{s}\right)$.

\subsubsection{Controlling for unobserved heterogeneity}

An implicit assumption of RE models is that the random component $v_{i}$ is uncorrelated with the explanatory variables. This may be seen as a rather strong assumption insofar as the dependent as well as the right-hand side variables may be driven by omitted characteristics. Thus, for example, predispositional happy individuals are more likely to marry and form larger households (Stutzer and Frey, 2006) and be more successful in life (Graham et al., 2004). The Mundlak term is intended to control for such correlations. It consists of a vector $\bar{X}_{i}^{M}$ with the time-averaged values of a subset of $M$ explanatory variables. These were chosen to be the time averaged value of years of schooling, number of children at home and number of adults ${ }^{3}$. With this strategy, the unobserved heterogeneity is assumed to consist of two parts, $v_{i}=u_{i}+\gamma \bar{X}_{i}^{M}$. The first part is a pure error term. The second varies linearly with the within-group means, whereby a possible correlation between the independent variables and the idiosyncratic characteristics is accounted for. Thus, Eq. (5) becomes

$$
S W B_{i t}^{*}=\beta X_{i t}+\gamma \bar{X}_{i}^{M}+\alpha_{l} \bar{y}_{i}+\alpha_{s} y_{i t}+\alpha_{c} y_{i t}^{c}+\alpha_{r} r_{i t}+u_{i}+\eta_{i t}
$$

\footnotetext{
${ }^{3}$ We call attention to the average income level $\bar{y}_{i}$ included in the regression, which can be regarded as part of the Mundlak term. However, for expositional purposes, we prefer to maintain a separate notation. Given its potential correlation with SWB and income, the proportion of years in employment during the observation period was also included as an additional Mundlak term in the earlier stages of the paper. This variable failed to be statistically significant in most specifications and was therefore dropped out.
} 
with $u_{i} \sim \mathrm{N}\left(0, \sigma_{u}^{2}\right), \eta_{i t} \sim \mathrm{N}(0,1), \operatorname{Cov}\left(u_{i}, \eta_{i t}\right)=0$.

The second extension regards the inclusion of explicit controls for the respondents' personality traits; the underlying assumption being that the most important component of individual heterogeneity in SWB equations is an individual's personality (Boyce, 2010). The BFI represents a widely accepted approach to conceptualizing personality as metaanalyses consistently support the construct validity of this approach (Costa and McCrae, 1992). After aggregating across items, the BFI provides a score for the five major traits that define human personality across cultures: Neuroticism, the tendency to experience negative emotions such as anxiety and depression; Extraversion, the tendency to be sociable, warm, active, assertive, cheerful, and in search of stimulation; Openness to experience, the tendency to be imaginative, creative, unconventional, emotionally and artistically sensitive; Agreeableness, the dimension of interpersonal relations, characterized by altruism, trust, modesty, and cooperativeness; and Conscientiousness, a tendency to be organized, strong-willed, persistent, reliable, and a follower of rules and ethical principles. The BFI questionnaire included in the 2005 wave of the SOEP is based on 3 items per personality dimension. All the items are answered on 7-point Likert type scales (ranging from 1 - "does not apply to me at all” to 7 - "applies to me perfectly") ${ }^{4}$. Although psychologists typically work with longer questionnaires, the shortened version used in this paper, known as the BFI-S, has been validated against longer inventories (Dehne and Schupp, 2007). A further issue of concern in personality measures is that the variability in the resulting scores arises from a measurement error. In our data, the encompassing tests of internal consistency were satisfactory ${ }^{5}$.

\footnotetext{
${ }^{4}$ The BFI items are: I see myself as someone who... i) worries a lot, ii) gets nervous easily, iii) is relaxed, handles stress well; iv) is communicative, talkative, v) is outgoing, sociable, vi) is reserved; vii) is original, comes up with new ideas, viii) values artistic experiences, ix) has an active imagination; $x$ ) is sometimes somewhat rude to others, $x i)$ has a forgiving nature, xii) is considerate and kind to others; xiii) does a thorough job, xiv) does things effectively and efficiently, xv) tends to be lazy. Neuroticism: i)-iii), Extraversion: iv)-vi), Openness to experience: vii)-ix), Agreeableness: x)-xii), Conscientiousness: xiii)-xv).

${ }^{5}$ A principal component analysis with varimax rotation was conducted. Factor analyses clearly replicated the Big Five factors by yielding a correlation matrix with five eigenvalues above unity. The five principal components accounted for $60.7 \%$ of the total variance. The Cronbach's alphas for the five dimensions were $0.627,0.660,0.620,0.505$ and 0.617 , respectively. For a given level of internal consistency, fewer items per dimension result in lower alphas (Mueller and
} 
This set of questions was complemented with measures of the respondents' locus of control (LOC). LOC is measured externally and internally. People with an external LOC believe that their behavior is guided by fate, luck, or other external circumstances, while those with an internal LOC believe that their behavior is guided by personal decisions and efforts. LOC is considered to be an important aspect of personality and, more importantly, the extent to which one finds social comparisons inspiring or threatening is known in the field of psychology to depend on whether one finds a sense of control over the dimension under evaluation (Lockwood, 2002). In the SOEP, LOC is surveyed with 10 items; four of which measure internal LOC and six of which measure external $\mathrm{LOC}^{6}$. As the a priori internal-external distinction was found to exhibit a limited amount of internal consistency in the data, a principal component analysis of all items was conducted ${ }^{7}$. Two underlying factors were identified and the corresponding scores used in the regressions.

Table 2 reports the average scores of the different personality dimensions. In the regressions stage of the paper, these were normalized to a mean zero and unit variance. As a final remark, the BFI and LOC information gathered in the 2005 wave of the SOEP were not surveyed in any of the previous or subsequent years. To deal with this limitation, it is assumed throughout the paper that these constructs are constant over time. This should not be seen as a stringent assumption as it is generally accepted that adults' personality traits are fairly stable over time (for meta-analyses, see Roberts and DelVecchio, 2000, Costa and McCrae, 2002). In the sample, respondents' mean age is 48 years and they are interviewed for no more than 7 consecutive years. The potential interdependency between early life events and personality should therefore not matter much.

\footnotetext{
Plug, 2006). Hence, although these reliability coefficients are toward the lower range of admissible values, they point to a reasonable amount of internal consistency given the low (3) number of items per personality trait.

${ }^{6}$ These are: i) My life course depends on me, ii) Influence on social conditions through involvement, iii) Success takes hard work, iv) Doubt my abilities when problems arise; v) Haven’t achieved what I deserve, vi) What you achieve depends on luck, vii) Others make the crucial decisions in my life; viii) Possibilities are defined by social conditions; ix) Abilities are more important than effort; $x$ ) Little control over my life. Internal LOC measured by i)-iv). External LOC measured by v)-x).

${ }^{7}$ The alpha reliability coefficient for internal LOC was very low (0.218). An alternative would have been to drop specific items in order to raise the reliability ratio or to exclude this dimension from the set of controls. The principal component analysis was chosen to extract the relevant information from all the items simultaneously.
} 
Insert Table 2 about here

\subsubsection{The GOP model}

The link between SWB and $\mathrm{SWB}^{*}$ is given by $S W B_{i t}=j$ if $\delta_{j-1} \leq S W B_{i t}^{*}<\delta_{j}$ for $j=1, \ldots, J$, with $J$ being the number of possible outcomes. While in the OP the cut-off points are fixed, in the GOP they depend on the model covariates, $\delta_{j}=\bar{\delta}_{j}+\theta_{i t j}$, where $\theta_{i t j}=\tilde{\beta}_{j} X_{i t}+\tilde{\gamma}_{j} \bar{X}_{i}^{M}+\tilde{\alpha}_{l j} \bar{y}_{i}+\tilde{\alpha}_{s j} y_{i t}+\tilde{\alpha}_{c j} y_{i t}^{c}+\tilde{\alpha}_{r j} r_{i t}$. Introducing individual heterogeneity in the cut-off points allows for differential responses on SWB for respondents with identical levels of true subjective well-being, SWB*. Technically, this refinement results in $J$ different vectors of coefficients, one for each specific outcome. The coefficients related to outcome $j$ are $\beta_{j}=\beta-\tilde{\beta}_{j}, \quad \gamma_{j}=\gamma-\tilde{\gamma}_{j}, \quad \alpha_{l j}=\alpha_{l}-\tilde{\alpha}_{l j}, \quad \alpha_{s j}=\alpha_{s}-\tilde{\alpha}_{s j}, \quad \alpha_{c j}=\alpha_{c}-\tilde{\alpha}_{c j}$, $\alpha_{r j}=\alpha_{r}-\tilde{\alpha}_{r j}$ where $\beta, \gamma, \alpha_{l}, \alpha_{s}, \alpha_{c}$, and $\alpha_{r}$ are the corresponding vectors in the OP. The probability of outcome $j$ is given by

$$
\operatorname{Prob}\left[S W B_{i t}=j\right]=\Phi\left(\bar{\delta}_{j}-\theta_{i t j}-u_{i}\right)-\Phi\left(\bar{\delta}_{j-1}-\theta_{i t j-1}-u_{i}\right)
$$

where $\Phi$ is the cumulative normal distribution. The impact of comparison income $y^{c}$ on the probability of outcome $j$ (i.e., the marginal probability effect, MPE) is

$$
\operatorname{MPE}_{j}\left(y^{c}\right)=\frac{\partial \operatorname{Prob}\left[S W B_{i t}=j\right]}{\partial y^{c}}=\varphi\left(\bar{\delta}_{j-1}-\theta_{i t j-1}-u_{i}\right) \alpha_{c j-1}-\varphi\left(\bar{\delta}_{j}-\theta_{i t j}-u_{i}\right) \alpha_{c j}
$$

where $\varphi$ is the normal density function. In this setting, the ratio of MPEs between household and comparison income (or, alternatively, rank) is allowed to differ across the $J$ outcomes, unlike in the $\mathrm{OP}^{8}$.

\footnotetext{
${ }^{8}$ The OP imposes $\theta_{i t j}=\bar{\theta}_{i t}$ for all $j$. In this case, and considering comparison and transitory income for instance, one gets from Eq. (8) that $M P E_{j}\left(y^{c}\right) / M P E_{j}(y)=a_{c} / a_{s}$, for all $j=1, \ldots, J$.
} 


\section{Results}

For reasons of space, only the coefficients of the income variables and rank will be reported. As only $2 \%$ of the sample individuals reports a SWB below 3 , responses 0 to 3 were regrouped into a single category and a modified 1-8 scale (8 being "totally happy") was used. All standard errors in the paper are corrected for clustered error terms at the reference group level ${ }^{9}$. Results excluding East Germany presented little variations and are available from the author upon request.

\subsection{The comparison income model}

Table 3 reports the results under specification 1. These are expressed in terms of Eq. (8): the figure in column $j$ for variable $k$ represents how the probability of outcome $j$ changes for a marginal increase in variable $k^{10}$. According to the OP estimates (panel 1), a higher family income reduces (raises) the probability of reporting low (high) SWB. The first row reports the MPE of transitory increases in income, $\operatorname{MPE}(y)$, whereas the impact of permanent increases is given by $\operatorname{MPE}(y)+\operatorname{MPE}(\bar{y})$. The effects are significant at the $1 \%$ level and somewhat smaller when variations are merely transitory. Thus, for example, a 1-unit increase in logarithmic transitory income (a 171.8\% increase in absolute levels) decreases the probability of reporting SWB $=1$ by 1.17 percentage points (pp), and raises the probability of reporting SWB $=8$ by almost the same magnitude $(1.13 \mathrm{pp})^{11}$. Inspection of the fourth row $(\operatorname{Prob}(\mathrm{SWB}=j)$ ) reveals that these figures represent more than a $40 \%$ variation relative to the average probability of these specific outcomes ( 2.4 and $2.3 \mathrm{pp}$, respectively). These probabilities increase by a factor of 2.1 if the variation in income is permanent.

\footnotetext{
${ }^{9}$ The assessment of the statistical significance of the effects reported in the paper is conservative, as clustering at the individual level resulted in approximately $30 \%$ lower standard errors.

${ }^{10}$ Alternatively, the MPE on the probability of reporting "at least $j$ " can be obtained by adding the MPEs reported in columns 1 to $j$.

${ }^{11} \mathrm{~A}$ 1-unit increase in logarithmic income corresponds to a 2.718 factor increase in absolute income. Smaller changes can be considered noting that a $x$ percent variation in absolute income corresponds to $\ln (1+x / 100)$ units of variation in logarithmic income.
} 
Insert Table 3 about here

As expected, $y^{c}$ exerts the opposite effect. A higher income benchmark raises the probability of reporting SWB $\leq 5$ and decreases the probability of SWB $>5$. To gauge the magnitude of these effects, the bottom part of the panel reports the tradeoff ratio between family and comparison income, which in the OP model is constant across outcomes of the dependent variable. A figure close to unity would suggest that SWB is totally relative in income. We find, however, that this is not the case. In terms of SWB, a $1 \%$ increase in $y^{c}$ is equivalent to a $0.485 \%$ decrease in transitory income and to a $0.275 \%$ decrease in permanent income. Still, one needs to test whether these figures are significantly different from unity in absolute value. The p-values of the corresponding $\chi^{2}$ statistics are attached to the tradeoff ratios reported in the table. The hypothesis that people care just as much about the level of income of the reference group as their own is rejected at the $1 \%$ level.

As a final remark, acknowledging the different dispersion of the variables involved leads to lower tradeoff ratios insofar as transitory $(S D=0.56)$ and permanent income (SD = 1.05) are more dispersed than comparison income $(S D=0.24)$. Specifically, an increase of one standard deviation in the comparison benchmark is equivalent in terms of SWB to a decrease of 0.27 standard deviations of transitory income and 0.06 standard deviations of permanent income.

\subsubsection{Question 1: Variations in the tradeoff ratios across the SWB distribution}

With an OP estimation, the income of the reference group is assumed to be as important for happiness (high SWB) as for unhappiness (low SWB). The GOP relaxes this assumption. Interestingly, we find that comparison income fails to be statistically significant to account for high levels (>6) of SWB. In these cases, the tradeoff with family income does not apply (marked with 'na' in the table). By contrast, comparison income predicts significantly the probability of reporting low levels of SWB. An alternative and perhaps more evocative interpretation refers to the well-being costs of comparison income between happy and unhappy individuals. Let us consider two individuals with the same vector of observable characteristics. One is completely happy with life, while the other is completely unhappy. In 
order to maintain the probability of reporting these specific outcomes unaltered after a $1 \%$ increase in comparison income, the unhappy individual should be compensated with a $0.682 \%$ increase in transitory income or, alternatively, a $0.474 \%$ increase in permanent income, whereas the happy individual does not require a compensation.

The extent of such inter-personal differences is not impressive, but calls for closer examination. When moving along the SWB distribution, the tradeoff between transitory and comparison income ranges from -1.027 to -0.616 , and it decreases further to -0.235 in the highest outcome. In this case, however, the statistic lacks an economic meaning as comparison income is not a relevant explanatory variable for this specific outcome. A similar reasoning applies to the tradeoff at SWB $=5$. Differences are even larger for the comparison-permanent income ratio, with the corresponding figures changing by almost one order of magnitude, from -0.250 to 1.781 . To test whether such differences are statistically significant, the bottom part of Table 3 tests the GOP against the OP. The first test is a global test in which the log-likelihood values of the restricted (OP) and the unrestricted (GOP) model are compared. The null hypothesis states that all the regressors are constant across the $J$ outcomes, while the alternative hypothesis relaxes this assumption. The likelihood ratio test consists of calculating the difference times two between the loglikelihood value of the restricted and the unrestricted model. This statistic follows a $\chi^{2}$ distribution with degrees of freedom equal to the number of restrictions, $(J-1) \times(K+M+3)$. According to its empirical value, 4,674.8, the OP is rejected. The next row presents a partial test which solely focuses on the income variables, with $\mathrm{H}_{0}: \alpha_{l j}=\alpha_{l}, \alpha_{s j}=\alpha_{s}$ and $\alpha_{c j}=\alpha_{c}$ for all $j=1, \ldots, \quad J$, and $\mathrm{H}_{1}: \alpha_{l j} \neq \alpha_{l m}, \alpha_{s j} \neq \alpha_{s m}$ or $\alpha_{c j} \neq \alpha_{c m}$ for some $j \neq m$. In this case, the unrestricted regression is given by a GOP in which all but the income variables have been restricted to be constant across the $J$ outcomes (degrees of freedom $=(J-1) \times 3$ ). Again, the null hypothesis is rejected, meaning that the equivalence between family and comparison income cannot be regarded as constant across the SWB distribution. 


\subsubsection{Question 2: the importance of being above or below the Joneses}

The second specification decouples the reference income variable $y^{c}$ into the variables richer and poorer. Such distinction improves the model fit, according to Akaike's information criterion $(\triangle \mathrm{AIC}=11.8 \text { in the } \mathrm{OP}, \Delta \mathrm{AIC}=38.2 \text { in the GOP })^{12}$.

The results in Table 4 unambiguously show that the comparison income effect depends on whether the individual is below or above the reference group. In the OP, the MPE of poorer is larger (in absolute terms) and more significant than the MPE of richer in all segments of the SWB distribution. This observation indicates that failing to keep up is a more relevant dimension of SWB than outperforming the Joneses. The equivalence scales in panel 1 are as follows. Let us consider an individual who is below the reference group (poorer $>0$ ) and sees this gap increased by $1 \%$. In order to maintain the probability of SWB $=1$ unaffected, this individual should be compensated by a $0.478 \%$ increase in permanent income or by a $2.264 \%$ increase in temporary income. The corresponding figures decrease to $0.258 \%$ and $1.225 \%$, respectively, if the individual is above the reference group (richer $>0$ ) and sees the gap reduced by $1 \%$. These compensations are constant across the distribution of outcomes.

Insert Table 4 about here

The GOP estimation relaxes this assumption (panel 2). Now, richer fails to be statistically significant to account for low levels $(<3)$ of SWB, while it significantly determines (at the $10 \%$ level) the probability of reporting high SWB. In other words, having one euro more than the Joneses might be a relevant source of happiness, but a largely irrelevant factor to escape from unhappiness. The effect of being below the Joneses is captured by poorer. In this case, a 1-euro increase in the gap between family and comparison income significantly raises the probability of low SWB. This effect is well-defined according to conventional statistical levels. However, the same increase does not reduce the probability of reporting a high (> 6) SWB score. This asymmetric effect suggests that failing to keep up with the Joneses significantly raises the likelihood of unhappiness, even though it does not prevent an individual from being remarkably happy. In fact, the income variables are no longer

\footnotetext{
${ }^{12}$ AIC $=-2 * \log -$ likelihood $+2 * \mathrm{k}$, where $k=$ number of parameters. $\Delta \mathrm{IAC}$ denotes the difference between specifications.
} 
interchangeable in the different SWB levels. When accounting for unhappiness, the tradeoff between family income and the richer variable does not apply. This stems from the fact that richer is not a relevant compensation variable in the lowest SWB levels, and the same occurs with poorer when SWB is high.

All in all, the GOP estimates provide a resounding 'no' for Question 2 of the paper. The tests reported in the bottom part of Table 4 again reject the restricted model, according to which the impact of richer and poorer on SWB is identical in different segments of the distribution.

\subsection{The rank-based status model}

In Specification 3, the underlying assumption is that SWB depends on the household rank within the reference group and not on income benchmarks. The results are reported in Table 5 and provide complementary support to the existence of relative effects. Still, this specification should be less preferred than specification $2(\Delta \mathrm{AIC}=18.8, \mathrm{OP} ; \Delta \mathrm{AIC}=33.9$, GOP).

In panel 1, rank exerts a positive, statistically significant effect upon SWB by decreasing the probability of reporting $\mathrm{SWB} \leq 5$ and raising the probability of SWB $>5$. Thus, for example, in going from the bottom to the top position of the ranking (a 1-unit variation in $r$ ), an individual sees the probability of SWB $=1$ reduced by $0.60 \mathrm{pp}$ and the probability of $\mathrm{SWB}=8$ increased by almost the same magnitude $(0.58 \mathrm{pp})^{13}$.

Insert Table 5 about here

The bottom part of the panel shows that a $1 \%$ ( 1 centile) variation in rank is equivalent to a $0.683 \%$ variation in transitory income and to a $0.254 \%$ variation in permanent income. In the latter case, the equivalence can be regarded as being significantly different from unity

\footnotetext{
${ }^{13}$ Rank may proxy for nonlinearities in the effect of family income. To rule out this concern, a third-order polynomial of $\log$ family income was included in the regression. The computations, which are not reported here, rendered similar estimates for the rank variable.
} 
according to the $\chi^{2}$ test. As the rank and income variables are measured in different units, and thus associated to different levels of dispersion, it is perhaps illustrative to report the tradeoff ratio in terms of standard deviations. Although not reported, the equivalence scales are: a one standard deviation in the individual rank (0.51) is equivalent to an increase in transitory and permanent income of 0.62 and 0.12 standard deviations, respectively.

\subsubsection{Question 3: Variations in the family income-rank tradeoff}

Panel 2 uncovers some differences across the SWB distribution regarding the rank effect. Now, rank fails to be a significant variable when accounting for high (>6) SWB, even though it significantly predicts low SWB. In other words, individual ranking is a relatively more important concern in the lower segments of the SWB distribution. This is captured by the rank-permanent income equivalence in terms of SWB, which is 0.587 and 0.668 when SWB $<3$. These figures more than double the average estimate given by the OP $(0.254)$, and contrast with the negligible compensations found for SWB $>6$. These results confirm the existence of asymmetries across the distribution and are further supported by the likelihood ratio tests reported in the bottom part of the table.

\subsection{Allowing for simultaneous effects}

The last specification moves on to allow for rank and comparison income effects simultaneously. The income of the reference group enters the equation in the preferred form, i.e., with the variables richer and poorer.

Panel 1 of Table 6 shows that SWB is simultaneously related to individual rank and poorer, and unrelated to richer. This result is interesting because it suggests that conditional on own rank, failing to keep up with the Joneses is an additional source of unhappiness. By contrast, for a given rank outpacing the Joneses does not result in additional happiness. Relative to specification 2, the addition of rank leaves the MPEs of household income practically unaltered and drives the coefficient of poorer and richer down. This is to be expected. Part of the comparison income effect is indeed due to rank differences: a greater reference 
income reduces, ceteris paribus, my own rank. As a result, the tradeoff ratio between poorer and transitory and permanent income decreases from 2.264 and 0.478 in specification 2, respectively, to 1.519 and 0.347 in specification 4 . By contrast, when moving from the pure rank model to the present model, the monetary equivalent of rank rises from 0.683 and 0.254 to 1.153 and 0.263 , respectively.

Insert Table 6 about here

Specification 4 provides a convenient benchmark to test the comparison income and the income rank hypotheses. Richer is definitely less relevant than rank, whereas the effect of poorer is only somewhat lower. Specifically, a decrease of 1-standard deviation in poorer (0.322) has the same effect on SWB as an increase in rank of 0.832 standard deviations. Still, the hypothesis that these impacts are equal but with opposite sign could not be rejected by the corresponding test. This finding departs from Boyce et al. (2010), who find strong support for the rank effect over the (non-significant) comparison income effect. The divergence with the present paper may be due to the treatment of unobserved heterogeneity, which is addressed here by means of panel methods. This view is consistent with the fact that using fixed effects, Clark et al. (2009a) report a coefficient of comparison income that is statistically significant and only $40 \%$ below that of rank. A second explanation is the diverging role of comparison income depending on whether individuals are above or below the average income in their group which, in the present paper, is explicitly taken into account.

\subsubsection{Question 4: Is individual rank the most relevant source of low and high SWB?}

Panel 2 of Table 6 allows for unrestricted effects. These may be somewhat obscured by changes in the statistical significance of the main variables when moving from the lower to the higher SWB levels. Indeed, most tradeoffs do not apply because they generally involve a variable that is not statistically significant for that specific outcome. Still, some patterns are apparent. The results can be summarized as follows. First, being unhappy ( $\mathrm{SWB} \leq 3)$ is closely related to the income gap with the Joneses if the gap is unfavorable (poorer $>0$ ) and, additionally, to individual rank. Second, an unfavorable gap does not prevent an 
individual from reporting high levels of SWB. Third, earning more income than the Joneses (richer $>0$ ) raises the probability of complete happiness, despite the effect is significant only at the $10 \%$ confidence level. By contrast, earning more income than the Joneses renders the probability of lower outcomes unaffected. Fourth, and turning to Question 4, the $\chi^{2}$ tests reject the hypothesis that rank is as important as (permanent) family income. It turns out that the most salient dimensions of complete happiness are richer and permanent family income, with the coefficients of these two variables being equal at conventional levels (pvalue $=0.181)$.

Finally, and from a more general perspective, the results confirm the findings from the previous models: a low rank and failing to keep up with the Joneses are particularly harmful for conditionally unhappy individuals and largely irrelevant among the happy. They also show that for a given rank, the unhappy additionally care about the income differential with the reference group if the differential is unfavorable.

\subsection{Robustness checks}

This paper avoids adding further complexity to the econometric model by instrumenting the household income variable. This choice is motivated by three reasons. Firstly, to date there is no standard procedure to apply IV in a generalized ordered probit model for panel data. Secondly, the added value of IV in the present setting is dubious. Any of the candidate variables available in the SOEP may have direct effects on SWB beyond those flowing indirectly through income. This problem may yield biased estimates and will be exacerbated by a weak correlation between the endogenous variable and the instruments (Bound et al., 1995). Thirdly, studies that have instrumented the income variable find higher not lower impacts of income on SWB (Luttmer, 2001, Powdthavee, 2010). The direction of this variation is important because the crux of our analysis is the tradeoff between relative income and own income. If the impact of own income is truly higher than predicted by our model, then the tradeoffs reported in the paper should be seen as a lower bound.

A natural concern is whether the findings of the paper are robust to changes in the definition of the reference groups. Although the combination of the different criteria 
outlined above is fairly rich by common standards, the approach is an exogenous one. The sensitivity of the estimates to changes in the definition of reference groups and variations in the level of aggregation within specific dimensions was explored using a 4-stage procedure. This consisted of successively adding the dimensions of gender, education and age to the pure geographical approach. Other sequences and different levels of aggregation within a given dimension were also considered. This included expanding the geographical classification from the East-West distinction to the 16 German states which, in the more elaborated model, resulted in 800 groups ${ }^{14}$. These alternative criteria gave rise to a large set of estimates which, for reasons of space, are not reported here. It will suffice to state that three important conclusions emerged from the results.

First, the average (OP) impact that comparison income and rank exert on SWB is fairly robust to the definition of the reference groups. Specifically, their tradeoff with family income changes by less than $30 \%$ when going from the pure geographical approach to the more elaborated model with 800 groups. Still, in the pure geographical model based solely on the East-West distinction rank and comparison income were found to be nonsignificant; a result that is arguably driven by the rough level of aggregation. Second, in all cases relative income effects were found to significantly change when moving from the lowest to the highest SWB levels, as has been reported thus far. Third, the changing role of richer and poorer across the SWB distribution was similar across definitions. Two exceptions were found under criteria abstracting from age differences. Whether such exceptions deserve further investigation remains an open question. It is very unlikely, however, that people abstract from life-cycle issues when conducting social comparisons, particularly those related to income. There exists a pronounced life-cycle behavior of income, with family resources rising by a factor of about 2 in European countries when going from young $(<25)$ to middle aged (50-55) cohorts (Budría and Díaz-Giménez, 2007). Neglecting the age component in the computations presumes that individuals do not take such statistical information into consideration.

\footnotetext{
${ }^{14}$ There are three types of regional variables in the SOEP. The more detailed classification is given by the German Regional Units (the Raumordnungsregionen), which are below the level of the federal states (16) and above the level of the counties (291). Such a disaggregation is not used in the present analysis.
} 
Overall, the sensitivity analyses suggest that the benchmark definitions used in this paper yield results that are similar to alternative group definitions. Problems of small size prevent us from exploiting more detailed classifications and considering additional socioeconomic dimensions.

\section{Conclusion}

This paper is the first to explore how and to what extent relative income effects change when moving from the lower to the upper segments of the SWB distribution. This was done by means of a Generalized Ordered Probit for panel data. The mean advantage of this approach is that it captures the varying role that the covariates play when accounting for different levels of SWB.

One robust result was obtained across specifications: relative income effects cannot be regarded as constant across the SWB distribution. Despite the pattern of variation being sensitive to the model specification, some results emerge from the data. First, relative income as measured either by the mean income of the reference group or the individual ordinal ranking within the group exerts a differential effect across SWB levels. The differences are statistically significant. Second, failing to catch up with the Joneses raises the probability of low SWB, but does not affect the probability of high SWB. By contrast, outperforming the Joneses is positively related to high SWB but unrelated to low SWB. Third, income rank is relatively more important in the lower than in the upper segments of the SWB distribution. Fourth, the results for the most comprehensive model show that conditional on rank, the unhappy additionally care about the income differential with the reference group if the differential is unfavorable.

Interestingly, the results are broadly consistent with previous findings from the field of psychology. These show that happy individuals are particularly successful at defending themselves against the potentially negative hedonic consequences of unfavorable comparisons and in using social comparison information strategically to increase their SWB. By contrast, unhappy individuals tend to interpret unfavorable social comparison information more pessimistically or to focus on their negative aspects (Lyubomirsky and 
Ross, 1997). While unhappy individuals have less conviction about their competence, happy individuals are known to think relatively more positively about themselves, feel more personal control, react more intensely to positive events and life outcomes and show shorter drops in affect in response to unfavorable life events (Campbell, 1990; Seidlitz et al., 1997; Lyubomirsky and Tucker, 1998). In the words of Lyubomirsky et al. (2001, pp. 513), "happy individuals respond in ways that seem to maintain and even promote their happiness and positive self-views, while unhappy individuals respond in ways that seem to support their unhappiness and negative self-views”. The results in this paper suggest that to a large extent this view can be expanded to the realm of income comparisons.

A complementary explanation for our findings also stems from the field of psychology. It is generally accepted that the mechanisms that give rise to positive emotions and happiness need not be the same as those that enhance negative emotions and unhappiness (Larsen and Prizmic, 2008). The different role played by comparison income and rank when accounting for high and low SWB levels is consistent with this view. Recently, Boes and Winkelmann (2009) have shown that the relationship between well-being and family income is not symmetric, with income being a more important source of negative well-being (when low) than of positive well-being (when high). According to the results, this also seems to be the case of unfavorable income comparisons and rank.

An agenda for further research is to explore how differences in personality shape the relationship between comparison information and SWB. In clinical and laboratory studies, responsiveness to social comparisons is found to greatly depend on long-lasting emotional states such as depression and on personality traits. Using income data would provide a pioneering view on the subject by economically appraising the extent and direction of such differences. 


\section{References}

Abel, A. (2008), Equity Premia with Benchmark Levels of Consumption: Closed-Form Results, in Rajnish Mehra (ed.), Handbook of the Equity Risk Premium, Amsterdam: Elsevier, 2008, pp. 117 $-157$.

Aspinwall, L. G. and S.E. Taylor (1993). Effects of social comparison direction, threat, and selfesteem on affect, self-evaluation, and expected success, Journal of Personality and Social Psychology, 64, 708-722.

Blanchflower and A. Oswald (2004), Well-being over time in Britain and the USA, Journal of Public Economics, 88, 1359-1386.

Boes, S., and R. Winkelmann (2009), The Effect of Income on General Life Satisfaction and Dissatisfaction, Social Indicators Research, 95, 111-128.

Bound, J., D. Jaeger and R. Baker (1995), Problems with Instrumental Variables Estimation when the Correlation Between the Instruments and the Endogenous Explanatory Variable is Weak, Journal of the American Statistical Association 90, 443-450.

Boyce, C. J. (2010). Understanding fixed effects in human well-being, Journal of Economic Psychology, 31, 1-16

Boyce, C., G. Brown and S. Moore (2010), Money and happiness: rank of income, not income, affects life satisfaction, Psychological Science, 21(4), 471-475.

Brown, G., J. Gardner and A. Oswald (2008), Does Wage Rank Affect Employees' Well-being?, Industrial Relations, 47(3), 355-389.

Budría, S. and J. Díaz-Giménez (2007), Economic inequality in Spain: The European Union Household Panel Dataset, Spanish Economic Review, 9, 1-38.

Cacioppo, J., L.C. Hawkley, A. Kalil, M.E. Hughes, L. Waite and R.A. Thisted (2008), Happiness and the Invisible Threads of Social Connection: The Chicago Health, Aging and Social Relations Study, in The Science of Subjective Well-Being, M. Eid and R.J. Larsen (Eds.), The Guilford Press, New York.

Campbell, J.D. (1990), Self-esteem and clarity of the self-concept, Journal of Personality and Social Psychology, 59, 538-549.

Campbell, J. and J. Cochrane (1999), By force of habit: A consumption-based explanation of aggregate shock market behavior, Journal of Political Economy, 107(2), 205-251.

Carroll, C., J. Overland, and D. Weil (2000), Saving and growth with habit formation, American Economic Review, 90(3), 341-355.

Clark, A.E., P. Frijters and M. Shields (2008a), Relative income, happiness and utility: an explanation for the Easterlin paradox and other puzzles, Journal of Economic Literature, 46, 95-144. 
Clark, A.E., E. Diener, Y. Georgellis and R.E. Lucas (2008b), Lags And Leads in Life Satisfaction: a Test of the Baseline Hypothesis, Economic Journal, 118(529), 222-243.

Clark, A., N. Kristensen and N. Westergaard-Nielsen (2009a), Economic Satisfaction and Income Rank in Small Neighbourhoods, Journal of the European Economic Association, 7(2-3), 519527.

Clark, A., N. Kristensen and N. Westergaard-Nielsen (2009b), Job Satisfaction and Co-Worker Wages: Status or Signal?, Economic Journal, 119(536), 430-447.

Clark, A.E., D. Masclet and M.-C. Villeval (2010), Effort and Comparison Income, Industrial and Labor Relations Review, 63, 407-426.

Clark, A. and C. Senik (2010), Who Compares to Whom? The Anatomy of Income Comparisons in Europe, Economic Journal, 120(544), 573-594.

Costa, P.T., and R.R McCrae (1992). NEO PI-R. Professional manual. Odessa, FL: Psychological Assessment Resources, Inc.

Costa, P. T. and R.R McCrae (2002). Looking backward: Changes in the mean levels of personality traits from 80 to 12. In D. Cervone and W. Mischel (Eds.), Advances in personality science, New York: Guilford Press, 219-237.

Danner, D., D.A. Snowdon and W.V. Friesen (2001), Positive emotions in early life and longevity: findings from the nun study, Journal of Personality and Social Psychology, 80, 804-813.

Dehne, M., and J. Schupp (2007), Personlichkeitsmerkmale im Sozio-oekonomischen Panel (SOEP): Konzept, Umsetzung und empirische Eigenschaften. DIW Berlin, Research Note 26.

Díaz, A., J. Pijoan-Mas and J.V Ríos-Rull (2003), Precautionary savings and wealth distribution under habit formation preferences, Journal of Monetary Economics, 50(6), 1257-1291.

Diener, E. and R. Lucas (1999), Personality and subjective well-being, in Well-being: the foundations of hedonic psychology, D. Kahneman, E. Diener and N. Schwarz (eds.). New York: Sage.

Di Tella, R., R. MacCulloch, and A. Oswald (2003), The macroeconomics of happiness, Review of Economics and Statistics, 85(4): 809-827.

Dittmann, J. And J. Goebel, (2010), Your House, Your Car, Your Education: The Socioeconomic Situation of the Neighborhood and its Impact on Life Satisfaction in Germany, Social Indicators Research, 96, 497-513.

Easterlin, R.A. (1974), Does economic growth improve the human lot? In: David, P.A., Reder, M.W. (Eds.), Nations and Households in Economic Growth: Essays in Honor of Moses Abramowitz. Academic Press, New York, 89-125.

Easterlin, R.A. (1995), Will raising the incomes of all increase the happiness of all? Journal of Economic Behavior and Organization, 27 (1), 35-47. 
Falk, A. And M. Knell (2004), Choosing the Joneses: Endogenous Goals and Reference Standards, Scandinavian Journal of Economics, Blackwell Publishing, 106(3), pages 417-435,

Ferrer-i-Carbonell, A. (2005), Income and Well-being: An Empirical Analysis of the Comparison. Income Effect, Journal of Public Economics, 89, 997-1019.

Frey, B. and Stutzer, A. (2002). What can economists learn from happiness research? Journal of Economic Literature, 40(2): 402-435.

Fuhrer, J. C. (2000), Habit formation in consumption and its implications formonetary policy models, American Economic Review, 90(3), 367-90.

Graham, C. A. Eggers and S. Sukhtankar (2004), Does happiness pay? An exploration based on panel data from Russia, Journal of Economic Behavior and Organization, 55, 319-342.

Heineck, G. and S. Anger (2010), The returns to cognitive abilities and personality traits in Germany, Labour Economics, 17(3), 535-546.

Helliwell, J.F. and Huang, H. (2010), How's the job? Well-being and social capital in the workplace', Industrial and Labor Relations Review, 63(2).

Huppert, F.A., and Whittington, J.E. (2003), Evidence for the Independence of Positive and Negative Well-Being: Implications for Quality of Life Assessment, British Journal of Health Psychology 8, 107-122.

Judge, T., D. Heller and M.K. Mount (2002), Five-factor model of personality and job satisfaction: A meta-analysis, Journal of Applied Psychology, 87, 530-541.

Larsen, R. And Z. Prizmic (2008), Regulation of Emotional Well-being: Overcoming the Hedonic Treadmill, in The Science of Subjective Well-Being, M. Eid and R.J. Larsen (Eds.), The Guilford Press, New York.

Lockwood, P. (2002), Could It Happen to You? Predicting the Impact of Downward Comparisons on the Self, Journal of Personality and Social Psychology, 82(3), 343-358.

Luttmer, E. (2005), Neighbours as negatives: Relative earnings and well-being, Quarterly Journal of Economics, 120, 963-1002.

Lyubomirsky, S., and Ross, L. (1997). Hedonic consequences of social comparison: A contrast of happy and unhappy people, Journal of Personality and Social Psychology, 73, 1141-1157.

Lyubomirsky, S. and K.L. Tucker (1998), Implications of individual differences in subjective happiness for perceiving, interpreting and thinking about life events, Motivation and emotion 22, 155-186.

Lyubomirsky, S., K.L. Tucker and F. Kasri (2001), Responses to hedonically conflicting social comparisons: Comparing happy and unhappy people, European Journal of Social Psychology, 31, 511-535. 
McBride, M. (2001), Relative income effects on subjective well-being in the cross-section, Journal of Economic Behavior and Organization, 45, 251-278.

Mueller, G. and E. Plug (2006), Estimating the Effect of Personality on Male-Female Earnings, Industrial and Labor Relations Review 60(1), 3-22.

Oswald, A. and S. Wu (2010), Objective Confirmation of Subjective Measures of Human Wellbeing: Evidence from the USA, Science 327(5965), 576-579.

Parducci, A. (1995), Happiness, pleasure, and judgment: the contextual theory and its applications, Erlbaum, Mahwah, NJ.

Powdthavee, N. (2009), How important is rank to individual perception of economic standing? A within-community analysis, Journal of Economic Inequality, 7(3), 225-248.

Roberts, B. W. and W.F. DelVecchio (2000), The rank-order consistency of personality from childhood to old age: A quantitative review of longitudinal studies, Psychological Bulletin, 126, 3-25.

Sapolsky, R.M. (2004), Social status and health in humans and other animals, Annual Review of Anthropololy 33, 393-318.

Seidlitz, L., R.S. Wyer and E. Diener (1997), Cognitive correlates of subjective well-being: The processing of valenced life events by happy and unhappy persons, Journal of Research in Personality, 31, 240-256.

Senik, C. (2004), When information dominates comparison: Learning from Russian subjective panel data, Journal of Public Economics, 88(9-10), 2099-2133.

Senik, C. (2005), What Can we Learn from Subjective Data ? The Case of Income and Well-Being, Journal of Economic Surveys, 2005, 19 (1), 43-63

Senik, C. (2009), Direct evidence on income comparisons and their welfare effects, Journal of Economic Behavior and Organization, 72(1), 408-424.

Stutzer, A. and B. Frey (2006), Does marriage make people happy, or do happy people get married?, The Journal of Socio-Economics, 35, 326-347.

van Praag, B.M.S. and A. Ferrer-i-Carbonell (2008), Happiness Quantified: A Satisfaction Calculus Approach, Oxford University Press. Revised edition.

van Praag, B.M.S. van and Ferrer-i-Carbonell, A. (2010), Happiness Economics: A new Road to Measuring and Comparing Happiness, Foundation and Trends in Microeconomics, 6(1), 1-97.

Van der Zee, K., F. Oldersma, B. Buunk and D. Bos (1998), Social comparison preferences among cancer patients as related to neuroticism and social comparison orientations, Journal of Personality and Social Psycology, 75, 801-810.

Wheeler, L. and K. Miyake (1992), Social comparison in everyday life, Journal of Personality and Social Psychology, 62, 760-773. 
Wood, J. V. and K. Van der Zee (1997), Social comparisons among cancer patients: Under what conditions are comparisons upward and downward? In B. P. Buunk and F. X. Gibbons (Eds.), Health, coping, and well-being: Perspectives from social comparison theory (pp. 299-328). Hillsdale, NJ: Erlbaum.

Zizzo, D.J (2002), Between utility and cognition: the neurobiology of relative position, Journal of Economic Behavior and Organization, 748, 71-91. 


\section{Tables}

Table 1. Summary statistics - Socioeconomic characteristics

\begin{tabular}{lrr}
\hline \hline & Mean & SD \\
\hline SWB & 6.998 & 1.659 \\
Age & 48.082 & 16.243 \\
Family income & 2922.080 & 2074.030 \\
Years of education & 12.083 & 2.656 \\
Number of children at home & 0.547 & 0.910 \\
Number of adults at home & 2.732 & 1.267 \\
Man & 0.479 & 0.500 \\
Living together & 0.647 & 0.478 \\
Divorced & 0.088 & 0.283 \\
Widowed & 0.060 & 0.237 \\
Single & 0.206 & 0.404 \\
Employed & 0.630 & 0.483 \\
Unemployed & 0.073 & 0.260 \\
Inactive & 0.297 & 0.457 \\
Westerner & 0.746 & 0.436 \\
Easterner & 0.254 & 0.436 \\
Badhealth & 0.163 & 0.370 \\
\hline
\end{tabular}

Table 2. Summary statistics - Personality traits

\begin{tabular}{lcc}
\hline \hline & Mean & SD \\
\hline Neuroticism & 3.968 & 1.218 \\
Extraversion & 4.828 & 1.130 \\
Openness to Experience & 4.497 & 1.201 \\
Agreeableness & 5.459 & 0.973 \\
Conscientiousness & 5.937 & 0.909 \\
Internal LOC & 5.182 & 0.717 \\
External LOC & 3.553 & 0.878 \\
\hline \hline
\end{tabular}


Table 3. Marginal probability effects of family and comparison income - Specification 1

\begin{tabular}{|c|c|c|c|c|c|c|c|c|}
\hline & \multicolumn{7}{|c|}{ SWB } & \multirow[b]{2}{*}{8} \\
\hline & 1 & 2 & 3 & 4 & 5 & 6 & 7 & \\
\hline \multicolumn{9}{|l|}{ Panel 1. OP estimation } \\
\hline MPE(y) & $\begin{array}{c}-0.0117^{* \star *} \\
-14.10\end{array}$ & $\begin{array}{c}-0.0099 \text { *** } \\
-14.10\end{array}$ & $\begin{array}{c}-0.0290 \text { *** } \\
-14.10\end{array}$ & $\begin{array}{c}-0.0203^{* * *} \\
-14.10\end{array}$ & $\begin{array}{c}-0.0110^{* * *} \\
-14.10\end{array}$ & $\begin{array}{c}0.0420 \text { ** } \\
-14.10\end{array}$ & $\begin{array}{c}0.0286 \\
-14.10\end{array}$ & $\begin{array}{c}0.0113^{\text {*** }} \\
-14.10\end{array}$ \\
\hline $\operatorname{MPE}(\bar{y})$ & $\begin{array}{c}-0.0153 \text { * } \\
-10.74\end{array}$ & $\begin{array}{c}-0.0130 \text { *** } \\
-10.74\end{array}$ & $\begin{array}{c}-0.0379{ }^{\star \star \star} \\
-10.74\end{array}$ & $\begin{array}{c}-0.0265 \text { *** } \\
-10.74\end{array}$ & $\begin{array}{c}-0.0144^{\star \star \star} \\
-10.74\end{array}$ & $\begin{array}{c}0.0549 \text { *** } \\
-10.74\end{array}$ & $\begin{array}{c}0.0374 \\
-10.74\end{array}$ & $\begin{array}{c}0.0148{ }^{* \star \star} \\
-10.74\end{array}$ \\
\hline $\operatorname{MPE}\left(\mathrm{y}^{\mathrm{c}}\right)$ & $\begin{array}{c}0.0074 * * * \\
3.78\end{array}$ & $\begin{array}{c}0.0063 * * * \\
3.78\end{array}$ & $\begin{array}{l}0.0184 * * * \\
3.78\end{array}$ & $\begin{array}{c}0.0129 * * * \\
3.78\end{array}$ & $\begin{array}{c}0.0070 \text { *** } \\
3.78\end{array}$ & $\begin{array}{c}-0.0266{ }^{* * *} \\
3.78\end{array}$ & $\begin{array}{c}-0.0181 * * * \\
3.78\end{array}$ & $\begin{array}{l}-0.0072 * * \star \\
3.78\end{array}$ \\
\hline \multirow[t]{3}{*}{$\operatorname{Prob}(\mathrm{SWB}=j)$} & 0.024 & 0.027 & 0.110 & 0.128 & 0.267 & 0.330 & 0.091 & 0.023 \\
\hline & \multicolumn{5}{|c|}{$\operatorname{MPE}\left(\mathrm{y}^{\mathrm{C}}\right) / \mathrm{MPE}(\mathrm{y})=-0.485\left(\operatorname{Prob}>\chi^{2}=0.009\right)$} & \multicolumn{3}{|c|}{ for all SWB $=1,2, \ldots, 8$} \\
\hline & \multicolumn{5}{|c|}{$\operatorname{MPE}\left(\mathrm{y}^{\mathrm{c}}\right) /(\operatorname{MPE}(\mathrm{y})+\operatorname{MPE}(\vec{y}))=-0.275\left(\operatorname{Prob}>\chi^{2}=0.000\right)$} & $\mathrm{r}$ all SWB $=1$ & $2, \ldots, 8$ & \\
\hline \multicolumn{9}{|l|}{ Panel 2. GOP estimation } \\
\hline MPE(y) & $\begin{array}{c}-0.0173 \star \star \star \star \\
-8.31\end{array}$ & $\begin{array}{c}-0.0132 \text { *** } \\
-5.69\end{array}$ & $\begin{array}{c}-0.0335{ }^{* * *} \\
-6.78\end{array}$ & $\begin{array}{c}-0.0177 \text { *** } \\
-2.98\end{array}$ & $\begin{array}{r}0.0053 \\
0.65\end{array}$ & $\begin{array}{c}0.0532 \text { *** } \\
6.51\end{array}$ & $\begin{array}{c}0.0150 * * \\
3.25\end{array}$ & $\begin{array}{c}0.0084{ }^{* \star \star} \\
3.68\end{array}$ \\
\hline $\operatorname{MPE}(\bar{y})$ & $\begin{array}{c}-0.0076 \text { ** } \\
-2.72\end{array}$ & $\begin{array}{c}-0.0101 \text { *** } \\
-3.42\end{array}$ & $\begin{array}{c}-0.0528{ }^{* *} \\
-8.30\end{array}$ & $\begin{array}{c}-0.0519 * * * \\
-7.22\end{array}$ & $\begin{array}{c}-0.0174 \text { * } \\
-1.78\end{array}$ & $\begin{array}{c}0.0779 * \star \\
7.54\end{array}$ & $\begin{array}{c}0.0510 \\
8.58\end{array}$ & $\begin{array}{c}0.0109{ }^{* \star \star} \\
3.77\end{array}$ \\
\hline $\operatorname{MPE}\left(\mathrm{y}^{\mathrm{c}}\right)$ & $\begin{array}{c}0.0118^{* \star \star} \\
2.84\end{array}$ & $\begin{array}{c}0.0136 \text { ** } \\
3.19\end{array}$ & $\begin{array}{c}0.0254^{\star \star *} \\
2.88\end{array}$ & $\begin{array}{r}0.0111 \\
1.14\end{array}$ & $\begin{array}{c}-0.0214 \text { * } \\
-1.65\end{array}$ & $\begin{array}{c}-0.0327 \\
-2.36\end{array}$ & $\begin{array}{r}-0.0057 \\
-0.71\end{array}$ & $\begin{array}{r}-0.0020 \\
-0.48\end{array}$ \\
\hline $\operatorname{Prob}(\mathrm{SWB}=j)$ & 0.026 & 0.027 & 0.105 & 0.126 & 0.268 & 0.327 & 0.094 & 0.026 \\
\hline $\operatorname{MPE}\left(\mathrm{y}^{\mathrm{c}}\right) / \mathrm{MPE}(\mathrm{y})$ & -0.682 & -1.027 & -0.756 & $-0.625^{\text {na }}$ & -4.023 na & -0.616 & -0.383 nа & $-0.235^{\text {na }}$ \\
\hline Prob $>\chi^{2}$ & 0.104 & 0.925 & 0.266 & 0.408 & 0.554 & 0.072 & 0.148 & 0.043 \\
\hline $\operatorname{MPE}\left(\mathrm{y}^{\mathrm{c}}\right) /(\operatorname{MPE}(\mathrm{y})+\operatorname{MPE}(\bar{y}))$ & -0.474 & -0.583 & -0.294 & $-0.159^{\text {na }}$ & $\begin{array}{r}1.781 \\
0.016\end{array}$ & -0.250 & $-0.087^{\text {na }}$ & -0.102 na \\
\hline Global test GOP against OP & $4,674.84 * \star \star 002$ & 0.020 & 0.000 & 0.000 & 0.010 & 0.000 & 0.000 & \\
\hline Partial test GOP against OP & $653.34 * \star *$ & & & & & & & \\
\hline No. of observations & 126,752 & & & & & & & \\
\hline
\end{tabular}

Notes to Table 3: i) z-ratios are in smaller type; ii) * denotes significance at the $10 \%$ level, ** denotes significance at the $5 \%$ level, *** denotes significance at the $1 \%$ level; iii) standard errors are corrected for clustering at the reference group level using block bootstrapping with n=50 number of extractions; iv) $y$ denotes family income, $\bar{y}$ denotes average family income over the sample period, $y^{c}$ denotes comparison income; $v$ ) the $\chi^{2}$ statistics (p-values) associated with the tradeoff ratios test whether the numerator and denominator are significantly different in absolute value; vi) ${ }^{\text {na }}$ : the tradeoff ratio does not apply because either the numerator or the denominator are not statistically significant; vi) additional controls: age and age squared, years of completed education, number of children at home and number of adults, gender, marital status (living together, divorced, widowed or single), employment status (employed, unemployed or inactive), region (West or East Germany), health condition (bad or good), year fixed effects and M=3 Mundlak correction terms; vii) Log-likelihood: OP model = -197113.1, GOP model = 194775.7; AIC OP model = 394296.1, AIC GOP model = 389621.3 
Table 4. Marginal probability effects of family and comparison income - Specification 2

\begin{tabular}{|c|c|c|c|c|c|c|c|c|}
\hline & \multicolumn{7}{|c|}{ SWB } & \multirow[b]{2}{*}{8} \\
\hline & 1 & 2 & 3 & 4 & 5 & 6 & 7 & \\
\hline \multicolumn{9}{|l|}{ Panel 1. OP estimation } \\
\hline MPE(y) & $\begin{array}{c}-0.0042 \text { ** } \\
-2.00\end{array}$ & $\begin{array}{c}-0.0036 \text { ** } \\
-2.00\end{array}$ & $\begin{array}{c}-0.0104 \text { ** } \\
-2.00\end{array}$ & $\begin{array}{c}-0.0073 \text { ** } \\
-2.00\end{array}$ & $\begin{array}{c}-0.0039 * \star \\
-2.00\end{array}$ & $\begin{array}{c}0.0150 * * \\
-2.00\end{array}$ & $\begin{array}{c}0.0102 \text { ** } \\
-2.00\end{array}$ & $\begin{array}{c}0.0040 \text { ** } \\
-2.00\end{array}$ \\
\hline $\operatorname{MPE}(\bar{y})$ & $\begin{array}{l}-0.0156 * * * \\
-10.91\end{array}$ & $\begin{array}{l}-0.0133 \text { *** } \\
-10.91\end{array}$ & $\begin{array}{c}-0.0388 \text { *** } \\
-10.91\end{array}$ & $\begin{array}{l}-0.0271 \text { *** } \\
-10.91\end{array}$ & $\begin{array}{c}-0.0148 \text { *** } \\
-10.91\end{array}$ & $\begin{array}{l}0.0562 * * * \\
-10.91\end{array}$ & $\begin{array}{c}0.0383 * * * \\
-10.91\end{array}$ & $\begin{array}{l}0.0151 * * * \\
-10.91\end{array}$ \\
\hline MPE(richer) & $\begin{array}{c}-0.0051 * * \\
-2.42\end{array}$ & $\begin{array}{c}-0.0044 \text { ** } \\
-2.42\end{array}$ & $\begin{array}{c}-0.0127 \text { ** } \\
-2.42\end{array}$ & $\begin{array}{c}-0.0089 * * \\
-2.42\end{array}$ & $\begin{array}{c}-0.0048 \text { ** } \\
-2.42\end{array}$ & $\begin{array}{c}0.0184 * * \\
-2.42\end{array}$ & $\begin{array}{c}0.0125 * * \\
-2.42\end{array}$ & $\begin{array}{c}0.0050 * * \\
-2.42\end{array}$ \\
\hline MPE(poorer) & $\begin{array}{c}0.0095 \text { *** } \\
4.52\end{array}$ & $\begin{array}{c}0.0080^{* * *} \\
4.52\end{array}$ & $\begin{array}{c}0.0234^{* * *} \\
4.52\end{array}$ & $\begin{array}{c}0.0164^{* * *} \\
4.52\end{array}$ & $\begin{array}{c}0.0089 \text { *** } \\
4.52\end{array}$ & $\begin{array}{c}-0.0340 * * * \\
4.52\end{array}$ & $\begin{array}{c}-0.0232{ }^{* * *} \\
4.52\end{array}$ & $\begin{array}{c}-0.0092 * * * \\
4.52\end{array}$ \\
\hline \multirow[t]{2}{*}{ Prob $(\mathrm{SWB}=j)$} & 0.024 & 0.027 & 0.110 & 0.128 & 0.267 & 0.330 & 0.091 & 0.023 \\
\hline & \multicolumn{5}{|c|}{$\begin{array}{c}\text { MPE }(\text { richer }) /(\operatorname{MPE}(\mathrm{y})+\operatorname{MPE}(\bar{y}))=0.258\left(\operatorname{Prob}>\chi^{2}=0.000\right) \\
\operatorname{MPE}(\text { poorer }) / \operatorname{MPE}(\mathrm{y})=-2.264\left(\text { Prob }>\chi^{2}=0.020\right) \\
\operatorname{MPE}(\text { poorer }) /(\operatorname{MPE}(\mathrm{y})+\operatorname{MPE}(\bar{y}))=-0.478\left(\operatorname{Prob}>\chi^{2}=0.000\right)\end{array}$} & \multicolumn{3}{|c|}{$\begin{array}{l}\text { for all } \operatorname{SWB}=1,2, \ldots, 8 \\
\text { for all } \mathrm{SWB}=1,2, \ldots, 8 \\
\text { for all } \mathrm{SWB}=1,2, \ldots, 8\end{array}$} \\
\hline \multicolumn{9}{|l|}{ Panel 2. GOP estimation } \\
\hline MPE(y) & $\begin{array}{r}-0.0051 \\
-1.11\end{array}$ & $\begin{array}{r}0.0005 \\
0.11\end{array}$ & $\begin{array}{r}-0.0079 \\
-0.78\end{array}$ & $\begin{array}{r}-0.0071 \\
-0.62\end{array}$ & $\begin{array}{r}-0.0168 \\
-1.11\end{array}$ & $\begin{array}{r}0.0205 \\
1.29\end{array}$ & $\begin{array}{r}0.0093 \\
1.01\end{array}$ & $\begin{array}{r}0.0065 \\
1.40\end{array}$ \\
\hline $\operatorname{MPE}(\bar{y})$ & $\begin{array}{c}-0.0086 \text { *** } \\
-3.05\end{array}$ & $\begin{array}{l}-0.0107^{* * *} \\
-3.62\end{array}$ & $\begin{array}{c}-0.0530 \text { *** } \\
-8.35\end{array}$ & $\begin{array}{c}-0.0512 \text { *** } \\
-7.14\end{array}$ & $\begin{array}{c}-0.0160 * \\
-1.65\end{array}$ & $\begin{array}{c}0.0788{ }^{* \star *} \\
7.66\end{array}$ & $\begin{array}{c}0.0502 \text { *** } \\
8.45\end{array}$ & $\begin{array}{l}0.0105^{* * *} \\
3.63\end{array}$ \\
\hline MPE(richer) & $\begin{array}{r}-0.0050 \\
-1.08\end{array}$ & $\begin{array}{r}-0.0088 \\
-1.00\end{array}$ & $\begin{array}{c}-0.0197 \text { ** } \\
-2.02\end{array}$ & $\begin{array}{r}-0.0133 \\
-1.22\end{array}$ & $\begin{array}{r}0.0108 \\
0.75\end{array}$ & $\begin{array}{r}0.0206 \\
1.35\end{array}$ & $\begin{array}{r}0.0111 \\
1.54\end{array}$ & $\begin{array}{c}0.0044 * \\
1.85\end{array}$ \\
\hline MPE(poorer) & $\begin{array}{c}0.0157 * * * \\
3.59\end{array}$ & $\begin{array}{c}0.0165 * * * \\
3.69\end{array}$ & $\begin{array}{c}0.0292 \text { *** } \\
3.15\end{array}$ & $\begin{array}{r}0.0098 \\
0.95\end{array}$ & $\begin{array}{c}-0.0295 \text { ** } \\
-2.13\end{array}$ & $\begin{array}{c}-0.0424 \text { *** } \\
-2.86\end{array}$ & $\begin{array}{r}-0.0001 \\
-0.02\end{array}$ & $\begin{array}{r}0.0008 \\
0.19\end{array}$ \\
\hline Prob $(\mathrm{SWB}=j)$ & 0.026 & 0.027 & 0.105 & 0.126 & 0.268 & 0.327 & 0.094 & 0.026 \\
\hline $\begin{array}{l}\text { MPE(richer)/MPE(y) } \\
\text { Prob }>\chi^{2}\end{array}$ & $\begin{array}{l}0.980^{\text {na }} \\
0.550\end{array}$ & $\begin{array}{c}-16.487^{\text {na }} \\
0.074\end{array}$ & $\begin{array}{l}2.513^{\text {na }} \\
0.270\end{array}$ & $\begin{array}{l}1.883^{\text {na }} \\
0.606\end{array}$ & $\begin{array}{l}-0.645^{\text {na }} \\
0.086\end{array}$ & $\begin{array}{c}1.002 \\
0.998\end{array}$ & $\begin{array}{l}1.191^{\text {na }} \\
0.856\end{array}$ & $\begin{array}{l}0.679 \text { na } \\
0.672\end{array}$ \\
\hline $\begin{array}{l}\text { MPE(richer)/(MPE }(y)+\operatorname{MPE}(\bar{y})) \\
\text { Prob }>\chi^{2}\end{array}$ & $\begin{array}{c}0.366^{\text {na }} \\
0.114\end{array}$ & $\begin{array}{c}0.863 \text { па } \\
0.807\end{array}$ & $\begin{array}{r}0.324 \\
0.001\end{array}$ & $\begin{array}{c}0.229 \text { па } \\
0.001\end{array}$ & $\begin{array}{c}-0.330^{\text {na }} \\
0.014\end{array}$ & $\begin{array}{l}0.207^{\text {па }} \\
0.000\end{array}$ & $\begin{array}{c}0.186 \text { na } \\
0.000\end{array}$ & $\begin{array}{r}0.258 \\
0.019\end{array}$ \\
\hline $\begin{array}{l}\text { MPE(poorer)/MPE(y) } \\
\text { Prob }>\chi^{2}\end{array}$ & $\begin{array}{l}-3.045^{\text {na }} \\
0.032\end{array}$ & $\begin{array}{l}31.096 \text { na } \\
0.001\end{array}$ & $\begin{array}{l}-3.721^{\text {na }} \\
0.042\end{array}$ & $\begin{array}{c}-1.382 \text { na } \\
0.819\end{array}$ & $\begin{array}{l}1.759 \text { na } \\
0.003\end{array}$ & $\begin{array}{c}-2.065 \text { na } \\
0.191\end{array}$ & $\begin{array}{l}-0.015^{\text {na }} \\
0.351\end{array}$ & $\begin{array}{l}0.130 \text { na } \\
0.139\end{array}$ \\
\hline $\begin{array}{l}\operatorname{MPE}(\text { poorer }) /(\operatorname{MPE}(\mathrm{y})+\mathrm{MPE}(\bar{y})) \\
\operatorname{Prob}>\chi^{2}\end{array}$ & $\begin{array}{r}-1.138 \\
0.723\end{array}$ & $\begin{array}{r}-1.628 \\
0.250\end{array}$ & $\begin{array}{r}-0.480 \\
0.006\end{array}$ & $\begin{array}{c}-0.168 \text { na } \\
0.000\end{array}$ & $\begin{array}{r}0.899 \\
0.000\end{array}$ & $\begin{array}{r}-0.427 \\
0.002\end{array}$ & $\begin{array}{l}-0.002 \text { na } \\
0.000\end{array}$ & $\begin{array}{l}0.049 \text { na } \\
0.001\end{array}$ \\
\hline Global test GOP against OP & $4,701.26 * * *$ & & & & & & & \\
\hline Partial test GOP against OP & $680.56 * * *$ & & & & & & & \\
\hline No. of observations & 126,752 & & & & & & & \\
\hline
\end{tabular}


Notes to Table 4: i) z-ratios are in smaller type; ii) * denotes significance at the $10 \%$ level, ** denotes significance at the $5 \%$ level, $* * *$ denotes significance at the $1 \%$ level; iii) standard errors are corrected for clustering at the reference group level using block bootstrapping with $\mathrm{n}=50 \mathrm{number}$ of extractions; iv) $y$ denotes family income, $\bar{y}$ denotes average family income over the sample period, $y^{c}$ denotes comparison income; v) the $\chi^{2}$ statistics (p-values) associated with the tradeoff ratios test whether the numerator and denominator are significantly different in absolute value; vi) ${ }^{\text {na. }}$ : the tradeoff ratio does not apply because either the numerator or the denominator are not statistically significant; vii) additional controls: age and age squared, years of completed education, number of children at home and number of adults, gender, marital status (living together, divorced, widowed or single), employment status (employed, unemployed or inactive), region (West or East Germany), health condition (bad or good), year fixed effects and M=3 Mundlak correction terms; viii) Log-likelihood: OP model = -197106.2, GOP model = -194755.5; AIC OP model = 394284.3, AIC GOP model $=389583.1$. 
Table 5. Marginal probability effects of family income and rank - Specification 3

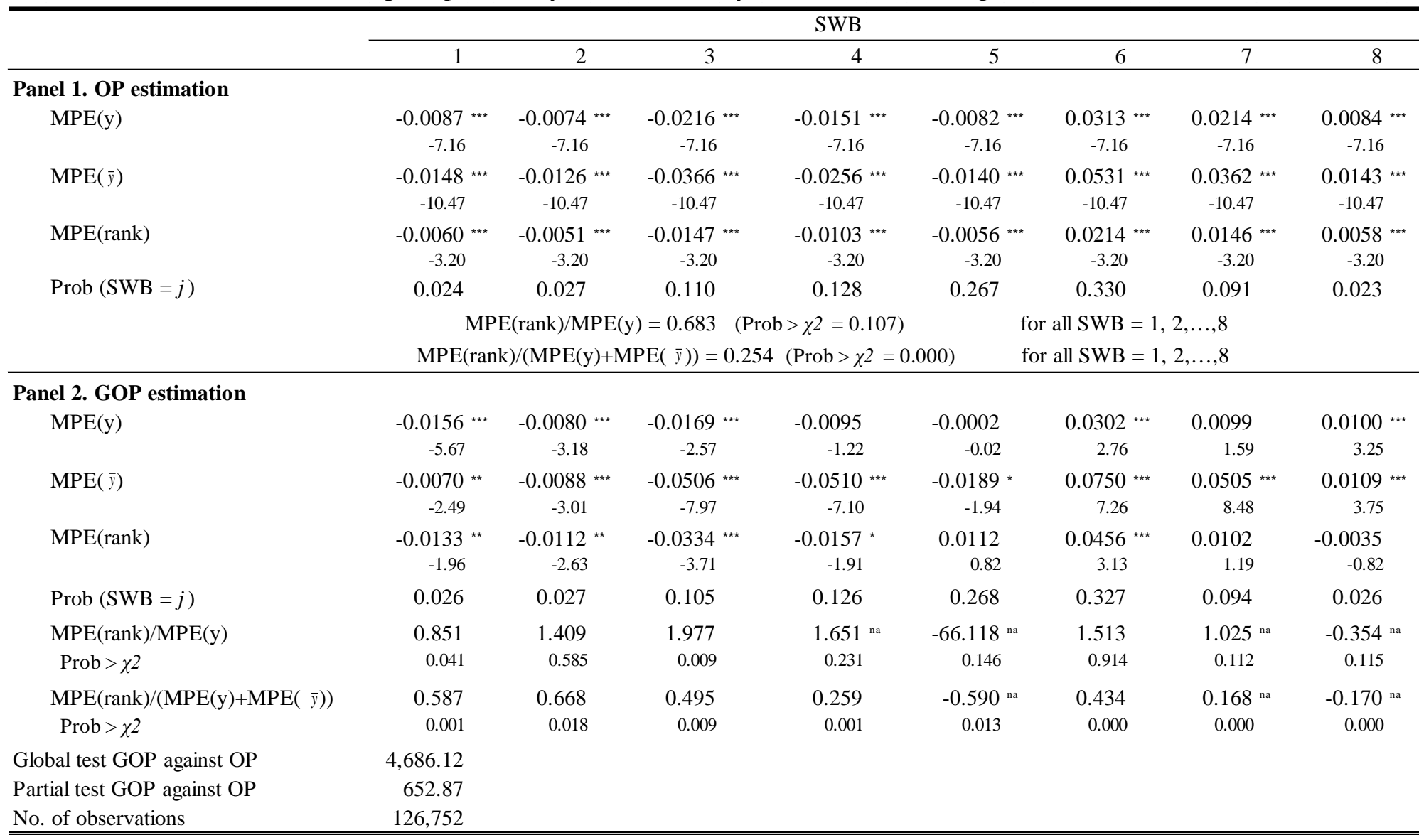

Notes to Table 5: i) z-ratios are in smaller type; ii) * denotes significance at the $10 \%$ level, ** denotes significance at the $5 \%$ level, $* * *$ denotes significance at the $1 \%$ level; iii) standard errors are corrected for clustering at the reference group level using block bootstrapping with $\mathrm{n}=50 \mathrm{number}$ of extractions; iv) $y$ denotes family income, $\bar{y}$ denotes average family income over the sample period, $r$ denotes individual rank; v) the $\chi^{2}$ statistics (p-values) associated with the tradeoff ratios test whether the numerator and denominator are significantly different in absolute value; vi) ${ }^{\text {na: }}$ the tradeoff ratio does not apply because either the numerator or the denominator are not statistically significant; vii) additional controls: age and age squared, years of completed education, number of children at home and number of adults, gender, marital status (living together, divorced, widowed or single), employment status (employed, unemployed or inactive), region (West or East Germany), health condition (bad or good), year fixed effects and $\mathrm{M}=3$ Mundlak correction terms; viii) Log-likelihood: OP model = -197117.2, GOP model = -194773.8; AIC OP model = 394303.1, AIC GOP model $=389617.0$ 
Table 6. Marginal probability effects of family income, comparison income and rank - Specification 4

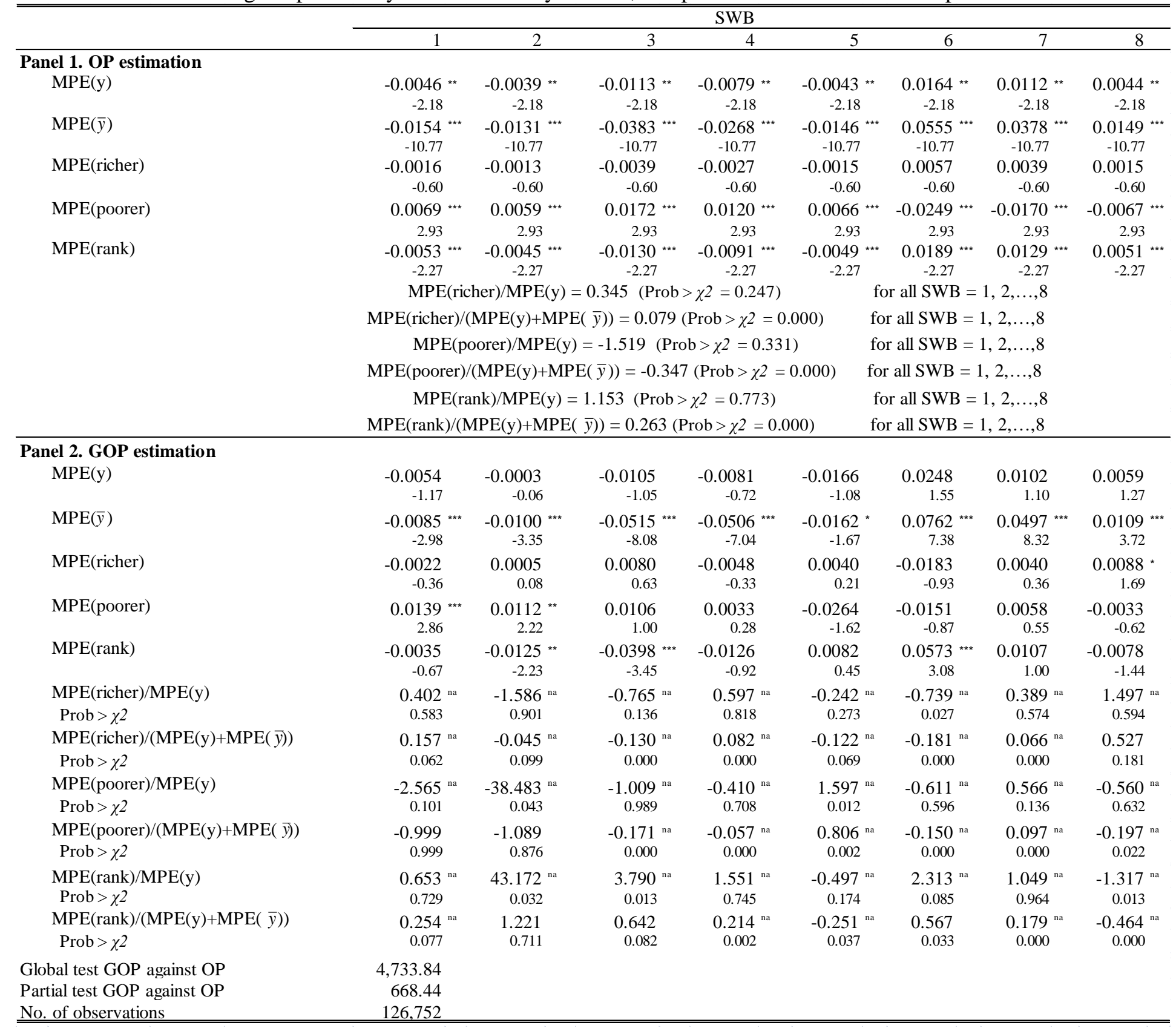


Notes to Table 6: i) z-ratios are in smaller type; ii) * denotes significance at the $10 \%$ level, $* *$ denotes significance at the $5 \%$ level, $* * *$ denotes significance at the $1 \%$ level; iii) standard errors are corrected for clustering at the reference group level using block bootstrapping with $\mathrm{n}=50 \mathrm{number}$ of extractions; iv) $y$ denotes family income, $\bar{y}$ denotes average family income over the sample period, $y^{c}$ denotes comparison income, $r$ denotes rank; v) the $\chi^{2}$ statistics (p-values) associated with the tradeoff ratios test whether the numerator and denominator are significantly different in absolute value; vi) ${ }^{\text {na }}$ : the tradeoff ratio does not apply because either the numerator or the denominator are not statistically significant; vii) additional controls: age and age squared, years of completed education, number of children at home and number of adults, gender, marital status (living together, divorced, widowed or single), employment status (employed, unemployed or inactive), region (West or East Germany), health condition (bad or good), year fixed effects and M=3 Mundlak correction terms; viii) Log-likelihood: OP model = -197101.8, GOP model = -194734.9; AIC OP model $=394277.6$, AIC GOP model $=389543.8$ 